\title{
CYCLING AND ACCUMULATION OF BIOGENIC SILICA AND ORGANIC MATTER IN HIGH-LATITUDE ENVIRONMENTS: THE Ross SEA
}

By David J. DeMaster, Robert B. Dunbar, Louis I. Gordon, Amy R. Leventer, John M. Morrison, David M. Nelson, Charles A. Nittrouer and Walker O. Smith, Jr.

... to identify the

primary location of the

fractionation between

fluxes of biogenic silica

and organic matter.
So jor sink for biogenic silica $(50-75 \%$ of the oceanic total of $4.5 \times 10^{14} \mathrm{~g} \mathrm{SiO}_{2} \mathrm{y}^{-1}$; DeMaster, 1981) but only a minor sink for organic carbon $(<1 \%$ of the oceanic $2 \times 10^{14}$ (g organic C) $\mathrm{y}^{-1}$; Romankevich, 1984). The high rates of biogenic silica accumulation in the Southern Ocean (predominantly beneath the Polar Front) initially were thought to result from high rates of primary production; however, direct measurements of primary production made during the past two decades (e.g., El-Sayed et al., 1983; Holm-Hansen et al., 1977) typically indicate that the rates in the Southern Ocean are low to moderate. These data suggest that the preservation efficiency for biogenic silica in the Southern Ocean plays a key role in the processes contributing to the massive silica accumulation. Primary production in the waters south of the Polar Front is not controlled by major nutrient (nitrate, phosphate, or silicate) availability (see Kamykowski and Zentara, 1989, for review) but may be restricted by low levels of irradiance coupled with deep mixed layers (e.g., Mitchell et al., 1991; Nelson and Smith, 1991) or by limited amounts of micronutrients such as iron (Martin et al., 1990). Regardless of the mechanism that limits biological production, Southern Ocean phytoplankton typically have a biogenic-silica-toorganic-carbon weight ratio ranging from 1 to 3 (Nelson and Smith, 1986). Therefore, the rela-

D.J. DeMaster and J.M. Morrison, Department of Marine, Earth, and Atmospheric Sciences, North Carolina State University, Raleigh, NC 27695-8208, USA. R.B. Dunbar, Department of Geology and Geophysics, Rice University, Houston, TX 77251-1892, USA. L.I. Gordon and D.M. Nelson, College of Oceanography, Oregon State University, Corvallis, OR 97331, USA. A.R. Leventer, Byrd Polar Research Center, Ohio State University, Columbus, OH 43214, USA. C.A. Nittrouer, Marine Sciences Research Center, State University of New York, Stony Brook, NY 11794-5000, USA. W.O. Smith, Jr., Botany Department and Program in Ecology, University of Tennessee, Knoxville, TN 37996, USA. tively high rates of biogenic silica accumulation in Southern Ocean sediments relative to organic carbon ( $\sim 60: 1$ on a weight basis) must result from the preferential preservation of biogenic silica in the Antarctic water column and/or seabed.

The focus of this high-latitude study has been to quantify the cycles of $\mathrm{Si}$ and organic $\mathrm{C}$ in the water column and seabed and to identify the primary location of the fractionation between fluxes of biogenic silica and organic matter. Measurements of uptake and regeneration rates were made for organic and siliceous phases throughout the upper $150 \mathrm{~m}$ of the water column. Particle traps were used to characterize changes in the nature of the biogenic particles within the water column at depths of 231 and $500-750 \mathrm{~m}$ below the ocean surface. Box cores and kasten cores were collected from the seabed to evaluate regeneration of biogenic phases below the sediment-water interface as well as accumulation rates of biogenic material in the sediment column.

The Ross Sea was chosen because it typifies many Antarctic settings and is characterized by 1) significant biogenic production and seabed accumulation (Ledford-Hoffman et al., 1986; Nelson and Smith, 1986), 2) relatively confined boundaries, 3 ) water circulation that is reasonably well understood (as compared with the complex dynamics of the Polar Front), and 4) close proximity to a major Antarctic support facility (McMurdo Station). A two-year time-series study has been conducted in an effort to minimize potential biases from short-term blooms and episodic changes in circulation and sedimentation. This paper describes several unique aspects of nutrient and carbon cycling in the high-latitude environment of the Ross Sea.

\section{Ross Sea Field Programs}

In January of 1990 the initial field program in the Ross Sea occupied 181 stations and deployed three moorings (Fig. 1A) from the research vessel 

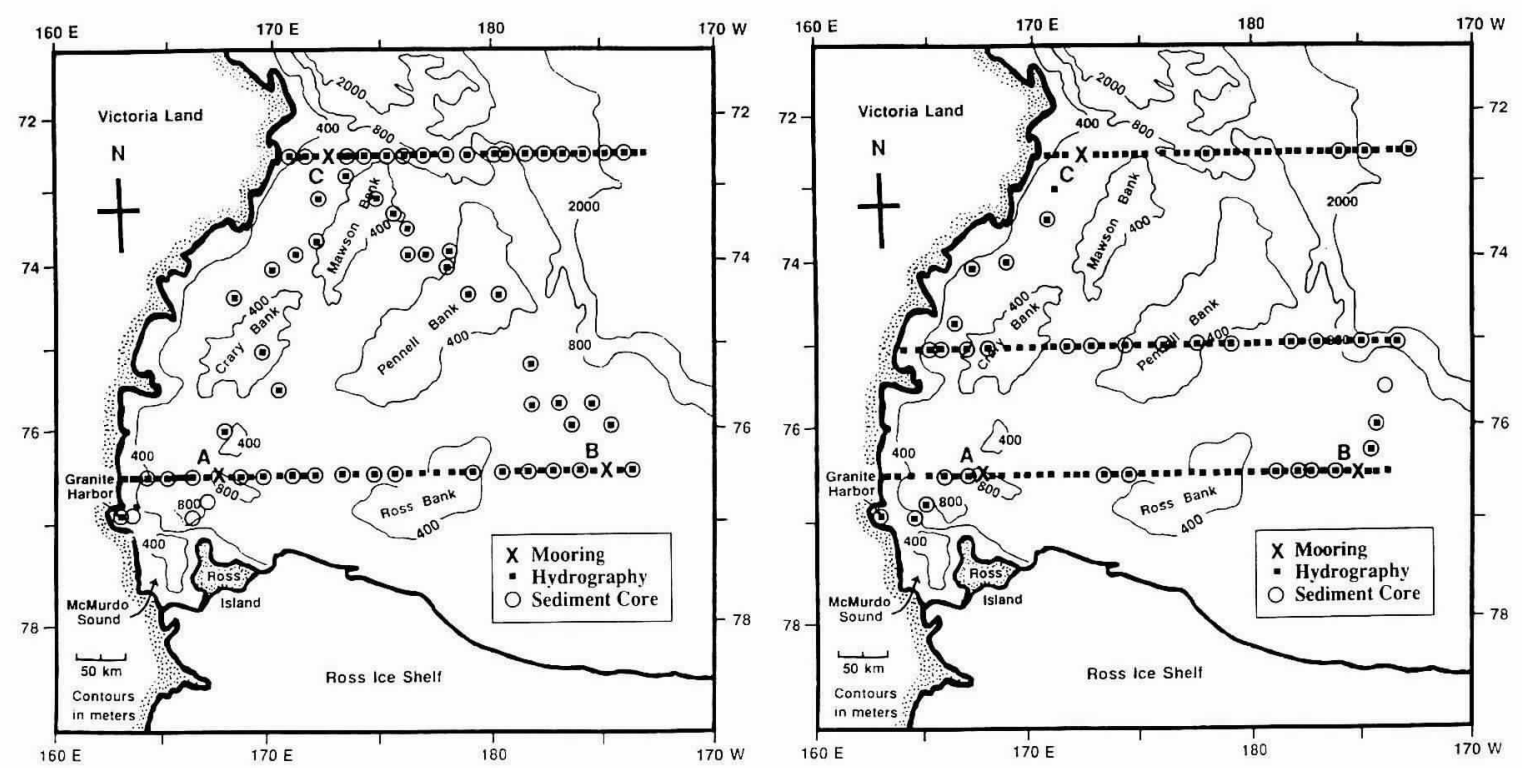

Fig. 1: Station locations from the 1990 and 1992 field cruises to the Ross Sea.

(R/V) POLAR DUKE. Two east/west transects were conducted during the cruise; one at $76^{\circ} 30^{\prime} \mathrm{S}$ and the other $72^{\circ} 30^{\prime} \mathrm{S}$. A conductivity-temperature-depth probe (CTD) equipped with a Sea Tech fluorometer and 10-cm-path-length Sea Tech transmissometer was deployed in the water column at every station. At every other station along the two transects, water samples for nutrients (nitrate, nitrite, ammonium, silicate, and phosphate), rate measurements $(\mathrm{C}, \mathrm{N}$, and $\mathrm{Si})$, and suspendedsolid analyses (chlorophyll, organic $\mathrm{C}$ and $\mathrm{N}$, and biogenic silica) were collected. Sediment cores were obtained from 65 stations, with porewater analyses and flux-core measurements (subcores incubated at in situ temperatures and sampled for changes in nutrient content in water overlying the subcore) used to evaluate the intensity of regeneration in the seabed.

Each of the three moorings consisted of two particle traps $\left(0.5-\mathrm{m}^{2}\right.$ cross-sectional area, rotating 15-cup design from Oregon State University); one $231 \mathrm{~m}$ below the ocean surface and the other $\sim 40$ $\mathrm{m}$ above the seabed $(500-750 \mathrm{~m}$ below the surface). The locations of the three mooring sites contrasted areas exhibiting differing sea-ice conditions during the austral summer and as such were expected to support different levels of primary production. Aanderaa current meters were placed just below each of the particle traps to monitor current speed and direction. In the bottom current meter at each site, a 25 -cm-pathlength Sea Tech transmissometer was placed in the directional vane to monitor particle concentration. At each of the mooring sites a string of three floating traps $\left(0.2-\mathrm{m}^{2}\right.$ cross-sectional area, depths 50-250 m) was deployed for a period of $24 \mathrm{~h}$. During a second occupation of the southern transect, Moorings $\mathrm{A}$ and $\mathrm{B}$ were retrieved and then redeployed after being out for a period of 23 and 14 days, respectively. One year later (January 1991) the Coast Guard Icebreaker POLAR SEA was used to retrieve and redeploy the moorings at sites $\mathrm{A}$ and $\mathrm{B}$.

During February 1992, the final Ross Sea cruises aboard the POLAR SEA and the R/V POLAR DUKE completed the time series and retrieved the three moorings. One hundred fortysix stations (Fig. 1B) were occupied with a protocol similar to that of the first cruise. A third east/west transect was added at $75^{\circ} \mathrm{S}$ to resolve differences in water-column and seabed characteristics in the northern and southern Ross Sea.

\section{Hydrography and Currents}

Water circulation in the Ross Sea generally is cyclonic (clockwise), with gentle southward flow in the central and eastern sections and intensified northward flow in the west (Klepikov and Grigor'yev, 1966; Jacobs et al., 1970; Pillsbury and Jacobs, 1985). Flow in the southern Ross Sea typically occurs in the westward direction. This circulation is best developed in surface waters but extends to depth as well. Tidal currents are an important process for mixing water masses in the study area, and current-meter records reveal distinct oscillations at tidal frequencies. Energy spectra reveal peaks at both semidiurnal $(0.08 \mathrm{cy}$ $\left.\mathrm{h}^{-1}\right)$ and diurnal $\left(0.04 \mathrm{cy} \mathrm{h}^{-1}\right)$ frequencies, but the diurnal signal dominates the current records. The data generally show a fortnightly modulation as well.

Current speeds can reach $25 \mathrm{~cm} \mathrm{~s}^{-1}$ at $240 \mathrm{~m}$ below the surface but are more typically $\sim 10 \mathrm{~cm}$ $\mathrm{s}^{-1}$. Maximum speeds are somewhat less in nearbottom records ( $40 \mathrm{~m}$ above the seabed), but typ-
... three mooring sites

contrasted areas

exhibiting differing

sea-ice conditions ... 
... this bloom had

developed within a lens

of low-salinity

meltwater... ical speeds are also $\sim 10 \mathrm{~cm} \mathrm{~s}^{-1}$. These speeds are probably insufficient to erode sediment from the seabed but could transport fine particles already in suspension. The deep currents at Mooring B have a net northwest displacement of $\sim 7 \mathrm{~km} \mathrm{~d}^{-1}$, whereas at Mooring A, the deep currents have a net northeastward displacement of $\sim 6 \mathrm{~km} \mathrm{~d}^{-1}$.

In the Ross Sea, suspended particulate matter has its highest concentrations near the water surface $\left(\sim 3 \mathrm{mg}^{-1}\right)$. Values abruptly decrease with depth (to $<0.1 \mathrm{mg} \mathrm{l}^{-1}$ ) but can show a small increase near the seafloor $\left(0.5 \mathrm{mg}^{-1}\right)$. The surface values generally result from biogenic material, whereas the bottom values reflect predominantly lithogenic material. The time-series records from transmissometers mounted on the moorings indicate uniformly low values for turbidity $(\leq 0.5$ $\mathrm{mg} \mathrm{^{-1 }}$ ).

\section{Distributions of Biogenic Silica, Nutrients, Chlorophyll, and Primary Production}

During the summers of both 1990 and 1992, the spatial distributions of phytoplankton biomass and nutrients in the upper water column of the Ross Sea were influenced strongly by an intense, diatom-dominated phytoplankton bloom in the vicinity of the receding ice edge (Fig. 2). As had been observed in previous years (e.g., Nelson and Smith, 1986; Smith and Nelson, 1985), this bloom had developed within a lens of low-salinity meltwater (which reduces vertical mixing in the euphotic zone and consequently promotes primary production). The area to the east of the ice-edge bloom revealed significant differences in nutrient and biomass distributions. During 1990, a second biogenic-silica maximum was observed near the eastern end of the southern transect. No such feature, however, occurred during the 1992 field season. The ice-edge assemblages in the southwestern Ross Sea were composed of mainly three pennate diatoms of the genus Nitzschia, whereas the bloom to the east had more diverse assemblages, with several centric diatoms and the nonsiliceous algae, Phaeocystis pouchetii, all abundant. Although the biogenic silica concentrations in these more easterly features were only about one-third as high as those within the bloom to the west (Fig. 2), they were still comparable with those found in highly productive, diatom-dominated coastal systems such as the Peru upwelling region (Nelson et al., 1981).

One of the potential causes of variability in silica and carbon accumulation rates within the Ross Sea is spatial variation in phytoplankton biomass and productivity (Smith and Nelson, 1990). Largescale patterns of algal standing stocks have been observed previously by nonsynoptic surveys (Holm-Hansen et al., 1977) and satellite composites (Smith and Sakshaug, 1990), but the causes of the observed differences remain elusive. During 1990 , large differences were noted in fluorescence

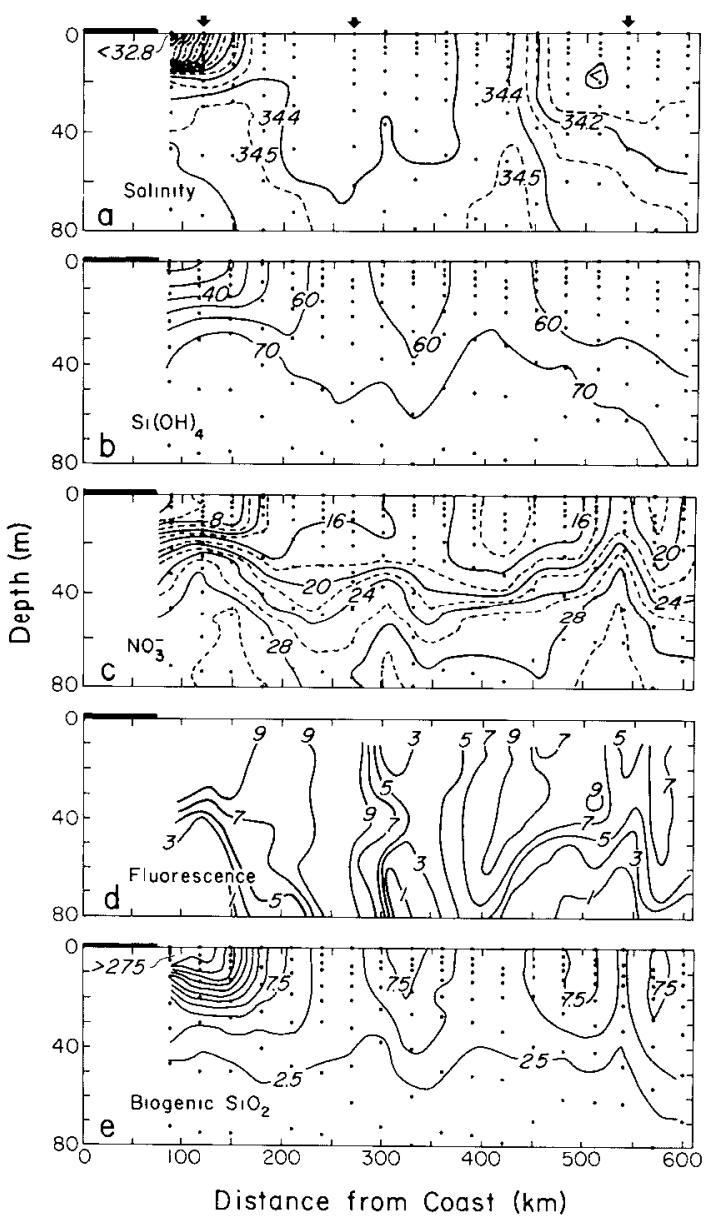

Fig. 2: Salinity, nutrients, biogenic silica, and fluorescence distributions during January 1990 along a $600 \mathrm{~km}$ east-west section in the southern Ross Sea $\left(76^{\circ} 30^{\prime}\right.$ S). Salinity contours are in practical salinity units (PSU), fluorescence contours are in relative units, and all other contours are in $\mu \mathrm{mol}$ $l^{-1}$. The black bar in each panel indicates the approximate location of the ice edge. Locations of the 3 stations for which profile data are presented in Figure 3 are shown at the top of a. Calibration of the fluorometers indicated that there is a good (1:1) correspondence between fluorescence and chlorophyll a. The ice-edge zone commonly exhibits high levels of chlorophyll and high rates of primary production as a result of enhanced stratification and a reduced vertical mixed layer.

between the southern and northern transects. High chlorophyll values at both ends of the southern transect were noted (surface values of $\sim 9 \mu \mathrm{g} \mathrm{l}^{-1}$ were observed), and elevated levels penetrated below $100 \mathrm{~m}$ (Fig. 2). In the northern transect, maximum chlorophyll concentrations were slightly $>2$ $\mu \mathrm{g}^{-1}$, and the spatial variations were much less pronounced. In 1992, the southern transect exhibited much lower levels than in 1990, with maximum concentrations of only $5 \mu \mathrm{g} \mathrm{l}^{-1}$.

The average primary productivity (based on ${ }^{14} \mathrm{C}$-uptake) in the southern transect during the 
1990 field season was double that found in the north (1.41 vs. $0.70 \mathrm{~g} \mathrm{C} \mathrm{m}^{-2} \mathrm{~d}^{-1}$, respectively), and this difference roughly parallels the difference observed in chlorophyll concentrations (integrated chlorophyll concentrations averaged 168 and 64 $\mathrm{mg} \mathrm{m}^{-2}$ in the south and north, respectively). Primary productivity in the southern transect in 1992 was moderate and averaged $0.83 \mathrm{~g} \mathrm{C} \mathrm{m}^{-2} \mathrm{~d}^{-1}$. The euphotic-zone chlorophyll concentrations along this transect in 1992 averaged $32 \mathrm{mg} \mathrm{m}^{-2}$.

\section{Production and Dissolution of Biogenic Silica}

Tracer studies were conducted with ${ }^{29} \mathrm{Si}$ and ${ }^{30} \mathrm{Si}$ to measure the production and dissolution rates of biogenic silica in the upper $50-80 \mathrm{~m}$ of the Ross Sea. Vertical profiles of biogenic silica concentrations and silica production rates from the 1990 field season are compared in Figure 3 at three representative stations: one within the iceedge bloom; one within a secondary biomass maxima to the east of the bloom; and one in an area of relatively low biomass. The higher silica production rates in the upper $20 \mathrm{~m}$ of the ice-edge zone (Fig. 3B) were observed consistently from mid-January through early February, 1990. Neither the concentration nor the production rate of biogenic silica at depths $>25-30$ m differed greatly between the ice-edge bloom area and rest of the Ross Sea.

On a vertically integrated basis, the mean production rate of silica within the ice-edge diatom bloom $\left(2.1 \mathrm{~g} \mathrm{SiO}_{2} \mathrm{~m}^{-2} \mathrm{~d}^{-1}\right)$ was approximately three times as great as that in areas away from the bloom $\left(0.72 \mathrm{~g} \mathrm{SiO}_{2} \mathrm{~m}^{-2} \mathrm{~d}^{-1}\right)$. Keeping the same assumptions used by Jones et al. (1990) regarding bloom duration and the rate of ice retreat, and including the 1990 field data showing significantly higher rates of silica production during summer in areas unaffected by the ice-edge bloom, yields a revised annual estimate of $21 \mathrm{mg} \mathrm{SiO} \mathrm{Sm}^{-2} \mathrm{y}^{-1}$, with the bloom accounting for $11 \mathrm{mg} \mathrm{SiO} \mathrm{cm}^{-2}$ $\mathrm{y}^{-1}$, or $55 \%$ of the annual total. For the 1990 field studies, the mass ratio of biogenic-silica production to organic-carbon production in the euphotic zone averaged 1.2 (range of $0.6-1.8$ ) within the ice-edge bloom and 0.80 (range of $0.2-1.4$ ) in other areas of the Ross Sea.

Measurements of silica dissolution rates in the upper water column of the southwestern Ross Sea show that on average $\sim 65 \%$ of the silica produced by diatoms in the euphotic zone dissolves within the upper $50 \mathrm{~m}$. This rather intense recycling of silica in the upper water column occurs even in the cold surface waters of the Ross Sea. because the low rates of silica dissolution are exceeded only to a small extent by the low specific rates of biogenic-silica production in this system (Nelson and Smith, 1986; Nelson et al, 1991). Applying this $65 \%$ dissolution term to the estimated annual rate of biogenic silica production $\left(21 \mathrm{mg} \mathrm{SiO} \mathrm{cm}^{-2}\right.$ $\mathrm{y}^{-1}$ ) yields a mean net silica production rate of

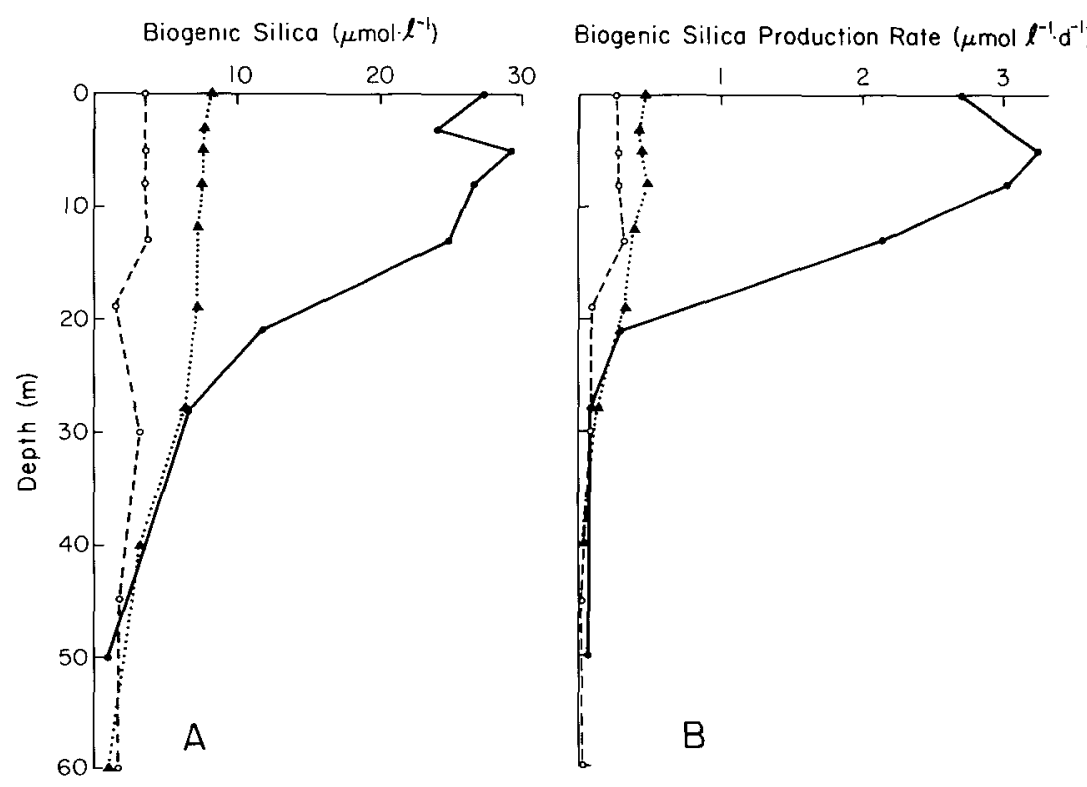

Fig. 3: Biogenic particulate silica $(A)$ concentrations and $(B)$ production rates at 3 stations representative of different biological conditions along the southern Ross Sea transect during January 1990. Closed circles denote station 4, within the main ice-edge diatom bloom; open circles denote station 8, within an area of low phytoplankton biomass; and triangles denote station 23, within a less pronounced biomass maximum $\sim 500 \mathrm{~km}$ east of the ice edge.

$7.4 \mathrm{mg} \mathrm{SiO} 2 \mathrm{~cm}^{-2} \mathrm{y}^{-1}$. This rate represents the excess of silica production over dissolution within the upper $50 \mathrm{~m}$ (where virtually all the siliceous biomass is found, see Fig. 2), and thus the highest mean silica flux through the water column that could be supported by local production.

\section{Particle-Trap Studies}

During mid-January through March 1990, the highest sediment fluxes (Fig. 4) occurred in the western Ross Sea (Site A), where samples exhibited high biogenic-silica contents (to $83 \%$ weight) and relatively low amounts of organic carbon ( 3 to $14 \%$ weight). Short-term sedimentation pulses (time scale of days) delivered as much as $1.5 \mathrm{~g}$ $\mathrm{SiO}_{2} \mathrm{~m}^{-2} \mathrm{~d}^{-1}$ and $0.18 \mathrm{~g}$ organic $\mathrm{C} \mathrm{m}^{-2} \mathrm{~d}^{-1}$ through the near-surface water column in this area. Nearly all biogenic silica delivered to the mid- and deep-water column consisted of unbroken tests of the diatom species Nitzschia curta, most of which had settled within ellipsoidal fecal pellets 150 to $300 \mu \mathrm{m}$ in length. At Site B (central Ross Sea) biogenic silica fluxes were nearly an order of magnitude lower than at Site A during January and early February of 1990 . The organic carbon fluxes were 2 to 4 times lower during this period, and the phytoplankton diversity was greater than at Site A. During mid-January through mid-March 1990, the high biogenic fluxes persisted in the western and central Ross Sea for 5-9 wk. In the western Ross Sea. at least two shortlived episodes of extremely high biogenic-silica flux occurred during this overall period of enhanced biogenic sedimentation (Fig. 4A). The ex- $\ldots \sim 65 \%$ of the silica

produced by diatoms in

the euphotic zone

dissolves within the

upper $50 \mathrm{~m}$. 


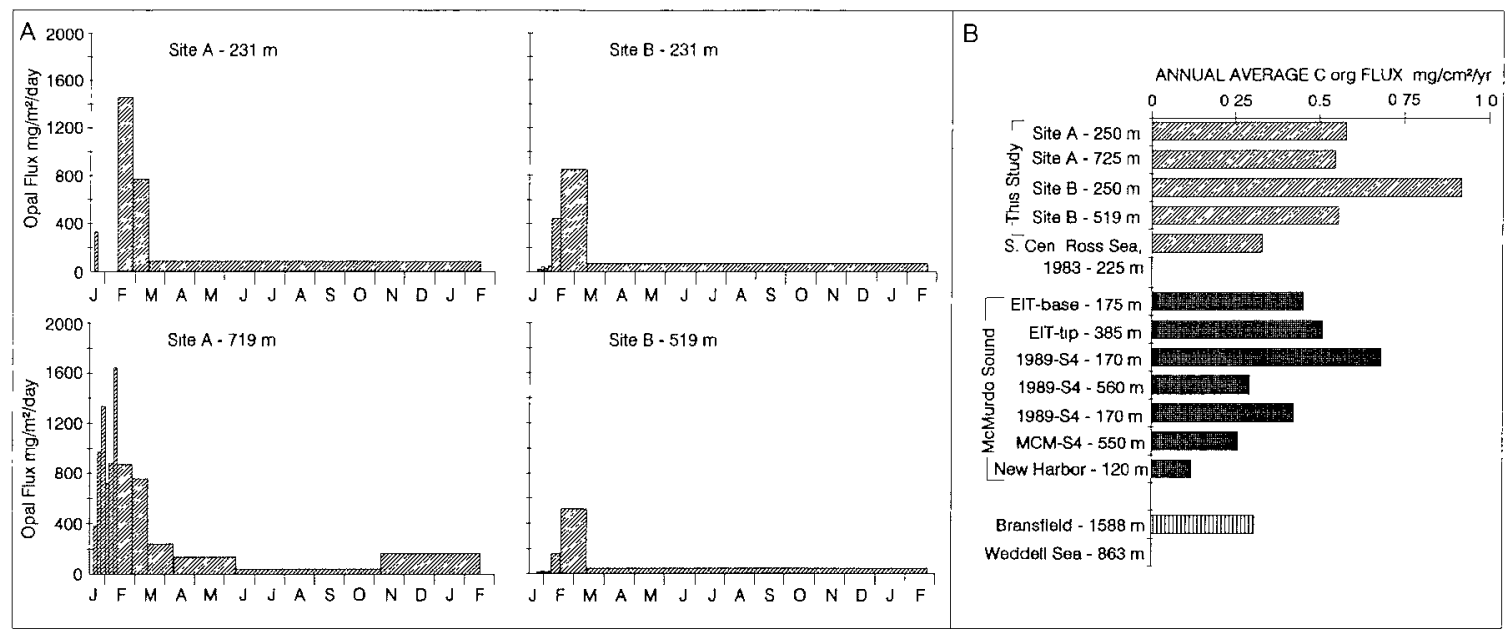

Fig. 4: (A) Histograms of biogenic silica flux to sediment traps deployed at sites $A$ and $B$ in the southern Ross Sea vs. time (expressed in months). Each bar represents a discrete measurement of biogenic-silica flux collected during the 13-month deployment period that began in January 1990. The particle-trap data show that most of the biogenic-silica flux occurs during January, February, and early March. The general agreement in flux between the upper and lower traps indicates that minimal dissolution occurs as the particles settle from depths of $231 \mathrm{~m}$ to depths of 500-750 in the water column. (B) Histogram of annual average organic-carbon flux (in $\mathrm{mg} \mathrm{cm}^{-2} \mathrm{y}^{-1}$ ) to sediment traps deployed in the central and western Ross Sea and in McMurdo Sound. Deployment periods ranged from 290 to 751 days. Source: south-central Ross Sea, Dunbar (1984); McMurdo Sound, Dunbar et al. (1989); Bransfield Strait, Wefer et al. (1988) and Fischer et al. (1988); Weddell Sea, Fischer et al. (1988).

tent to which this episodicity is controlled by dayto-day changes in primary production versus the feeding activities of zooplankton is unknown.

Results from the first year's deployment show that biogenic sedimentation at Site B increased to levels roughly equivalent to Site A during midFebruary through mid-March (Fig. 4A). Sinking debris in the central Ross Sea was consistently enriched in organic $C$ relative to Site $A$ at all depths. This may be a function both of the greater proportion of production by nonsiliceous algae (e.g., Phaeocystis pouchetii) and the specific diatom assemblage in the central Ross Sea. For example, $N$. cylindrus, a commonly observed diatom, tends to be underrepresented in the seabed because of its small and fragile frustule. Biogenic fluxes decrease markedly at both sites during the austral winter (Fig. 4A).

Biogenic-silica-to-organic-carbon mass ratios in trap samples from Sites $A$ and $C$ increase with depth, from values of $2-5$ at $50 \mathrm{~m}$ below the sea surface to values of $10-50$ at $40 \mathrm{~m}$ above the seafloor. It appears that considerable decoupling of organic $\mathrm{C}$ and silica occurs during settling through the water column, in part because of oxidative loss of organic carbon. Advective transport also plays a role in the biogenic silica enrichment in deep-trap samples at Site A. During nearly all periods when time-synchronous samples are available, near-bottom biogenic silica and lithogenic fluxes in the western Ross Sea are larger than in the upper water column (231 $\mathrm{m}$ depth). This is the opposite of the trend observed in the central
Ross Sea and is consistent with advective transport of siliceous debris to the western Ross Sea.

The annual biogenic-silica flux for the upperwater-column trap ( $231 \mathrm{~m}$ depth) at Site A is 5.6 $\mathrm{mg} \mathrm{cm} \mathrm{cm}^{-2} \mathrm{y}^{-1}$ and is greater than the upper trap value at Site $B, 3.5 \mathrm{mg} \mathrm{cm}^{-2} \mathrm{y}^{-1}$. The annual biogenic-silica fluxes in the near-bottom traps at these two sites also differ, with Site A having a flux of $7.8 \mathrm{mg} \mathrm{cm}^{-2} \mathrm{y}^{-1}$ and Site B having a flux of 2.4 $\mathrm{mg} \mathrm{cm}{ }^{-2} \mathrm{y}^{-1}$. The annual average organic-carbon fluxes at Sites A and B range from $0.51-0.91 \mathrm{mg}$ $\mathrm{cm}^{-2} \mathrm{y}^{-1}$ (Fig. 4B) for the surface traps. The nearbottom traps at these sites have annual organiccarbon fluxes that are nearly identical $(0.51 \mathrm{mg}$ $\mathrm{cm}^{-2} \mathrm{y}^{-1}$ ).

\section{Seabed Fluxes of Biogenic Material}

Rates of sediment accumulation in Ross Sea sediments were determined by measuring the downcore decrease in ${ }^{14} \mathrm{C}$ activity of the sediment's organic matter. The diversity in Ross Sea depositional environments is evident by contrasting sediment accumulation rates at Granite Harbor, Site A, and Site B (Fig. 5). Granite Harbor, a coastal basin, has the highest rate of accumulation with a value of $250 \mathrm{~cm} \mathrm{ky}^{-1}$. The sediments at Site $A$ are intermediate with a rate of $16 \mathrm{~cm} \mathrm{ky}^{-1}$, and the Site B sediments accumulate the most slowly at a rate of $\sim 1 \mathrm{~cm} \mathrm{ky}^{-1}$ during the past 10,000 years. These data reveal a two-order of magnitude gradient in accumulation rate in the southern Ross Sea within a distance of $<600 \mathrm{~km}$. 

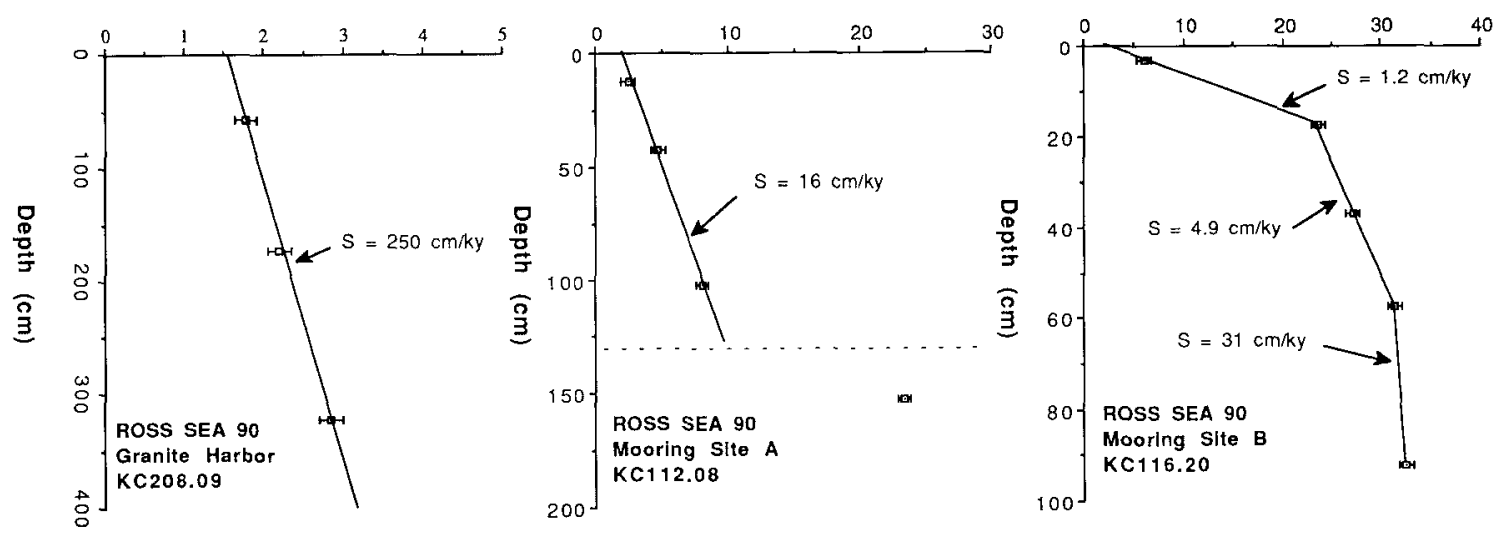

Fig. $5:{ }^{14} \mathrm{C}$ chronologies from 3 field sites located in the southern Ross Sea. Sediment accumulation rates vary by more than 2 orders of magnitude over a spatial scale of $<600 \mathrm{~km}$.

This trend in accumulation rates is consistent with general patterns of Ross Sea sedimentation and the thickness of Holocene sediments revealed in seismic profiles (Anderson et al., 1984).

The sediments in Granite Harbor consist of $40 \%$ biogenic silica and $\sim 1.8 \%$ organic carbon, whereas the sediments at Site A consist of $38 \%$ biogenic silica but only $1.1 \%$ organic carbon. The sediments at Site B contain the least amount of biogenic material with only $4 \%$ biogenic silica and $0.37 \%$ organic carbon. The biogenic-silica and organic-carbon accumulation rates were calculated from these data. Rates were highest in Granite Harbor $\left(40 \mathrm{mg} \mathrm{SiO}_{2} \mathrm{~cm}^{-2} \mathrm{y}^{-1}\right.$ and $1.8 \mathrm{mg} \mathrm{C} \mathrm{cm}^{-2}$ $\left.\mathrm{y}^{-1}\right)$, intermediate at Site $\mathrm{A}\left(2.6 \mathrm{mg} \mathrm{SiO}_{2} \mathrm{~cm}^{-2} \mathrm{y}^{-1}\right.$ and $0.08 \mathrm{mg} \mathrm{C} \mathrm{cm}^{-2} \mathrm{y}^{-1}$ ), and very low at Site B $\left(0.04 \mathrm{mg} \mathrm{SiO}_{2} \mathrm{~cm}^{-2} \mathrm{y}^{-1}\right.$ and $0.004 \mathrm{mg} \mathrm{C} \mathrm{cm}^{-2}$ $\left.\mathrm{y}^{-1}\right)$.

Regeneration rates for biogenic silica and organic matter were evaluated by incubating flux cores (i.e., subcores $7-14 \mathrm{~cm}$ in diameter, inserted into a box core immediately after collection) over a period of several days and monitoring the increase in nutrient concentration (silicate, phosphate, ammonium, and nitrate) in the water overlying the sediment as a function of time. Porewater nutrient concentrations also were measured on box-core and kasten-core samples as a check on the flux-core data. The dissolved-silica flux out of the seabed ranged from $5.4 \mathrm{mg} \mathrm{SiO} \mathrm{cm}^{-2} \mathrm{y}^{-1}$ in Granite Harbor to $2.2 \mathrm{mg} \mathrm{SiO}_{2} \mathrm{~cm}^{-2} \mathrm{y}^{-1}$ at Site B. Organic-carbon regeneration rates (calculated from phosphate data in flux cores and the assumed Redfield composition for organic matter) ranged from $0.56 \mathrm{mg} \mathrm{C} \mathrm{cm}{ }^{-2} \mathrm{y}^{-1}$ in Granite Harbor to $0.23 \mathrm{mg} \mathrm{C} \mathrm{cm}{ }^{-2} \mathrm{y}^{-1}$ at Site B. By adding the seabed-regeneration flux to the sediment-accumulation flux, the amount of biogenic silica or organic carbon arriving at the sediment/water interface was calculated. Although there was not a large difference in the absolute seabed regenera- tion rates among the 3 sites, there is a dramatic difference spatially in the seabed preservation efficiencies for these two biogenic phases. The seabed preservation efficiency (biogenic accumulation rate divided by the flux reaching the seafloor) is very high in Granite Harbor for both biogenic silica (88\%) and organic carbon (77\%). At Site A, $47 \%$ of the biogenic silica reaching the seafloor accumulated in seabed, whereas only $13 \%$ of the organic carbon was preserved. The preservation efficiencies for material arriving at the seabed were lowest at Site B with only $2 \%$ of the biogenic silica and $2 \%$ of the organic carbon ultimately preserved in the sediment column.

\section{Discussion and Summary}

One of the unique aspects of this study is that it brings together all of the necessary flux measurements to assess the cycling of biogenic silica and organic matter both in the water column and seabed. Figure 6 shows the biogenic silica and organic carbon fluxes for Site $\mathrm{A}$ as an example of this overall approach. The fractionation between biogenic silica and organic matter is evident from the fluxes as well as the consistent increase in the biogenic-silica-to-organic-carbon ratio with depth. The primary separation in biogenic silica and organic carbon fluxes at Site A occurs in the upper $200 \mathrm{~m}$ of the water column where the silica flux decreases by only a factor of 3 or 4 (relative to gross production), and the organic-carbon flux decreases by a factor of 28 . In the lower water column there appears to be relatively little fractionation between biogenic silica and organic carbon, whereas degradation at the sediment/water interface releases organic carbon to a greater extent than biogenic silica. Twelve percent of the biogenic silica produced in the euphotic zone ultimately accumulates in the seabed at Site A, whereas $<0.5 \%$ of the surface organic-carbon production is preserved in the sedimentary record.
... degradation at the

sediment/water

interface releases

organic carbon to a

greater extent than

biogenic silica. 


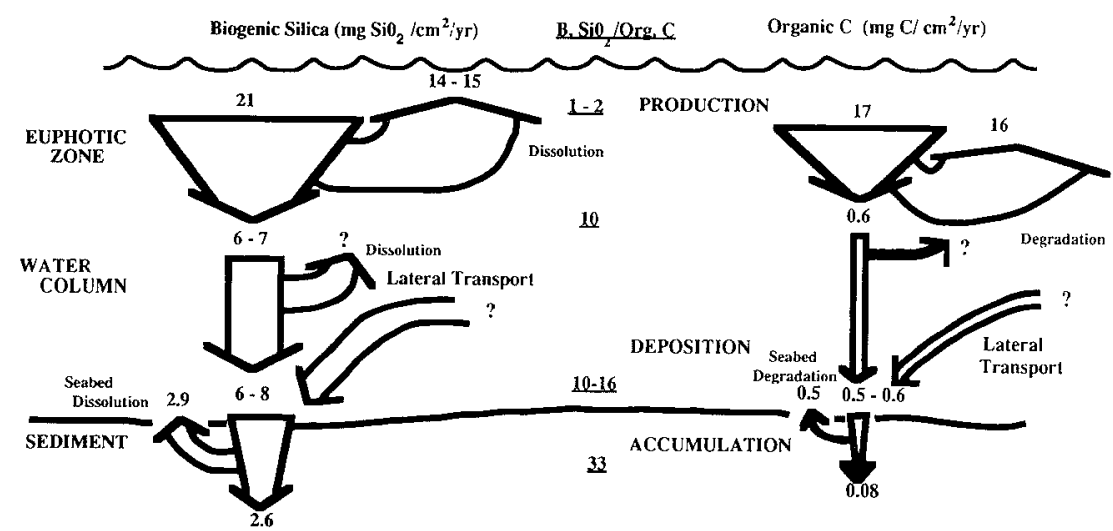

Fig. 6: Summary of biogenic-silica and organic-carbon fluxes at Mooring Site A. The preferential preservation of biogenic silica relative to organic carbon is evident in the steadily increasing ratio of silica/organic $C$ as a function of depth in the water column and seabed. Thirty-five percent of the biogenic silica produced in the euphotic zone survives dissolution within the surface layer, whereas only $4 \%$ of the organic carbon escapes microbial degradation in these near-surface waters. The accumulation of biogenic silica in the seabed represents $12 \%$ of the surface production, whereas the seabed organic-carbon accumulation rate accounts for $<0.5 \%$ of the surface production.

\section{... polar sediments}

account for most of

the ocean's biogenic

silica accumulation but

only a small amount of

the sedimentary

organic-carbon flux.
The regeneration mechanisms are inherently different for biogenic silica (inorganic dissolution) and organic carbon (microbial degradation). By contrasting sites with varying productivities and accumulation rates, the factors controlling these fractionating processes continue to be examined. The importance of lateral transport at Site A is unknown at this time; however, the two-year current-meter records and transmissometer data are being examined in an effort to quantify this flux.

The vertical fluxes at Site A are comparable to annual average fluxes in western McMurdo Sound (Dunbar et al., 1989) and are similar to or slightly greater than the near-bottom carbon flux reported by Wefer et al. (1988) and Fischer et al. (1988) beneath the highly productive waters of the Bransfield Strait (Fig. 4B). These studies observed a similar pattern of enhanced summer biogenic sediment flux, with $>90 \%$ of the annual biogenic sediment flux occurring during a 2- to 6-week period from late November through January. Biogenic flux events in much of the Ross Sea appear to occur during late January through March, notably later than in the Antarctic Peninsula region. It is likely that melting and breakup of the annual fast ice, which occurs later in the higher-latitude Ross Sea than in the area of the Antarctic Peninsula, exert a strong control on the timing and duration of annual blooms.

To place the results of this high-latitude study in perspective, a comparison of the Ross Sea data with global biogenic fluxes is useful. The total oceanic production rate for biogenic silica is $\sim 1.2$ $\times 10^{16} \mathrm{~g} \mathrm{y}^{-1}$ (Calvert, 1983; Brzezinski, 1985), whereas the rate of seabed accumulation is only
$0.04 \times 10^{16} \mathrm{~g} \mathrm{y}^{-1}$ (DeMaster, 1981), or $\sim 4 \%$ of production. Estimates of the oceanic organic-carbon production rate are $\sim 2.7 \times 10^{16} \mathrm{~g} \mathrm{C} \mathrm{y}^{-1}$ (Eppley and Peterson, 1979) as compared with a seabed accumulation rate of $0.02 \times 10^{16} \mathrm{~g} \mathrm{y}^{-1}$ (Broecker and Peng, 1982; Romankevich, 1984), equivalent to $0.7 \%$ of production. In the Ross Sea (Site A), 12\% of the biogenic silica produced in surface waters accumulates in the sediments below, which is considerably greater than the percentage for the world ocean. In contrast, $\sim 0.5 \%$ of the surface organic-carbon production in the Ross Sea accumulates in the seabed, which is comparable to the world oceanic value. The enhanced preservation of biogenic silica in the Ross Sea relative to organic carbon is consistent with the fact that polar sediments account for most of the ocean's biogenic silica accumulation (50-75\%) but only a small amount of the sedimentary organic-carbon flux $(<1 \%)$.

\section{Acknowledgements}

This research was funded by the National Science Foundation, Division of Polar Programs. We thank the officers and crews of the POLAR DUKE and POLAR SEA for their efforts and diligence. We also thank our co-workers and colleagues who have aided us and encouraged us throughout this research program.

\section{References}

Anderson, J.B., C.F. Brake and N.C. Meyers, 1984: Sedimentation on the Ross Sea continental shelf, Antarctica. Mar. Geol., 57, 295-333.

Brzezinski, M.A., 1985: The Si:C:N ratio of marine diatoms: interspecific variability and the effect of some environmental variables. J. Phycol., 21, 347-357.

Broecker, W.S. and T.H. Peng, 1982: Tracers in the Sea. Columbia University Press, Palisades, NY, 687 pp.

Calvert, S.E., 1983: Sedimentary geochemistry of silicon. In: Silicon Geochemistry and Biogeochemistry. S.R. Aston, ed., Academic Press, London, 143-186.

DeMaster, D.J., 1981: The supply and accumulation of silica in the marine environment. Geochim. Cosmochim. Acta, 45, 1715-1732.

Dunbar, R.B. 1984: Sediment trap experiments on the Antarctic continental margin. Antarct. J. U.S. 19, 70-71. A.R. Leventer and W.L. Stockton, 1989: Biogenic sedimentation in McMurdo Sound, Antarctica. Mar. Geol., 85, 155-179.

El-Sayed, S.Z., D.C. Biggs and O. Holm-Hansen, 1983: Phytoplankton standing crop, primary productivity, and near-surface nitrogenous nutrient fields in the Ross Sea, Antarctica. Deep Sea Res., 30, 871-886.

Eppley, R.W. and B.J. Peterson, 1979: Particulate organic matter and planktonic new production in the deep ocean. Nature, 282, 677-680.

Fischer, G., D. Futterer, R. Gersonde, S. Honjo, D. Ostermann and G. Wefer, 1988: Seasonal variability of particle flux in the Weddell Sea and its relation to ice cover. Nature. $335,426-428$.

Jacobs, S.S., A.F. Amos and P.M. Bruchhausen, 1970: Ross Sea oceanography and Antarctic Bottom Water formation. Deep Sea Res., 17, 935-962.

Jones, E.P., D.M. Nelson and P. Treguer, 1990: Chemical Oceanography. In: Polar Oceanography. W.O. Smith, Jr., ed., Academic Press, New York, 407-476.

Holm-Hansen, O., S.Z. El-Sayed, G.S. Franceschini and R.L. 
Cuhel, 1977: Primary production and factors controlling growth in the Southern Ocean. In: Adaptations Within Antarctic Ecosystems. G. Llano, ed., Gulf Publishing, Houston, TX, 11-50.

Kamykowski, D. and S.J. Zentara, 1989: Circumpolar plant nutrient covariation in the Southern Ocean: patterns and processes. Mar. Ecol. Prog. Ser., 58, 101-111.

Klepikov, V.V. and Y.A. Grigor'yev, 1966: Water circulation in the Ross Sea. Sov. Antarct. Exped. Rep., 6, 52-54.

Ledford-Hoffman, P.A., D.J. DeMaster and C.A. Nittrouer, 1986: Biogenic silica accumulation in the Ross Sea and the importance of Antarctic continental shelf deposits in the marine silica budget. Geochim. Cosmochim. Acta, 50, 2099-2110.

Martin, J.H., R.M. Gordon and S.E. Fitzwater, 1990: Iron in Antarctic waters. Nature, 345, 156-158.

Mitchell, B.G., E.A. Brody, O. Holm-Hansen, C. McClain and J. Bishop, 1991: Light limitation of phytoplankton biomass and macronutrient utilization in the Southern Ocean. Limnol. Oceanogr., 36, 1662-1677.

Nelson, D.M., J.A. Ahern and L.J. Herlihy, 1991: Cycling of biogenic silica within the upper water column of the Ross Sea. Mar. Chem., 35, 461-476.

J.J. Goering and D.W. Boisseau, 1981: Consumption and regeneration of silicic acid in three coastal upwelling systems. In: Coastal Upwelling. F.A. Richards, ed., Amer. Geophys. Union, Washington, D.C., 242-256. and W.O. Smith, Jr., 1986: Phytoplankton bloom dynamics of the western Ross Sea ice edge. II. Mesoscale cycling of nitrogen and silicon. Deep Sea Res., 33, 13891412.

and W.O. Smith, Jr., 1991: Sverdrup revisited: critical depths, maximum chlorophyll levels, and the control of southern ocean productivity by the irradiance-mixing regime. Limnol. Oceanogr., 36, 1650-1661.

Pillsbury, R.D. and S.S. Jacobs, 1985: Preliminary observations from long-term current meter moorings near the Ross Ice Shelf, Antarctica. In: Oceanology of the Antarctic Continental Shelf, S.S. Jacobs, ed., Antarctic Research Series, Vol. 43, American Geophysical Union, Washington, $\mathrm{DC}$, pp. 87-107.

Romankevich, E.A., 1984: Geochemistry of Organic Matter in the Ocean. Springer-Verlag, New York, $334 \mathrm{pp}$.

Smith, W.O., Jr. and D.M. Nelson, 1985: Phytoplankton bloom produced by a receding ice edge in the Ross Sea: spatial coherence with the density field. Science, 227, 163-166. and D.M. Nelson, 1990: Primary productivity and nutrient uptake in an Antarctic marginal ice zone during austral spring and autumn. Limnol. Oceanogr., 35, 809821.

and E. Sakshaug, 1990: Autotrophic processes in polar regions. In: Polar Oceanography. W.O. Smith, Jr., ed., Academic Press, New York, 477-525.

Wefer, G., G. Fischer, D. Futterer and R. Gersonde, 1988: Seasonal particle flux in the Bransfield Strait. Deep Sea Res., 35, 891-898. 